\title{
Processos de revitalização urbana e a percepção dos usuários
}

\author{
Margarita Barretto ${ }^{1}$ \\ Fundação Universidade Regional de Blumenau \\ Universidade Federal de Santa Catarina
}

Resumo: $O$ objetivo desta pesquisa foi registrar a percepção de diferentes atores sociais sobre o processo de revitalização da rua Vidal Ramos, no centro histórico da cidade de Florianópolis. Foi realizada uma pesquisa documental e etnográfica, com observação não participante, entrevistas semi estruturadas e registro fotográfico. $O$ estado atual da rua foi aprovado por todos os atores sociais entrevistados, que incluiram idealizadores do projeto, lojistas, moradores e transeuntes. Tratou-se de uma pesquisa exploratória, com duração de apenas uma semana, cujos resultados podem contribuir com as discussões sobre revitalização e gentrificação e constitui uma inovação enquanto tema de pesquisa na cidade de Florianópolis.

Palavras-chave: Patrimônio; Revitalização Urbana; Percepção.

Abstract: The aim of this study was to record the perception of different social agents regarding the regeneration process of rua Vidal Ramos (Vidal Ramos street) in the bistoric centre of the city of Florianópolis. A documentary and ethnographic study was carried out that involved non-participant observation, semi-structured interviews and a photographic record. All the social agents interviewed approved of the current state of the street; these included the project's designers, shop-owners, residents and non-residents. The results of this exploratory study, which lasted barely a week, will contribute to discussions regarding regeneration and gentrification and represents an innovation regarding research into the city of Florianópolis.

Key words: heritage, urban regeneration, perception.

1. Doutora em Educação. Docente do Mestrado em Administração da FURB e do Mestrado em Arquitetura da UFSC. Pesquisadora do CNPq. Graduanda do Curso de Museologia da UFSC. 


\section{Introdução}

Os espaços públicos são, ou deveriam ser, para todos. No entanto na medida do crescimento das cidades houve uma apropriação de alguns setores das mesmas por diferentes atores sociais, o que foi levando aos poucos à segregação espacial. Dito de outra forma, tomando de empréstimo observações de Leite (2002) o espaço urbano deixa de ser público; passa a ser de certa forma "privatizado" para uso de um grupo social e não por estar interditado para os outros grupos, mas porque estes últimos evitam aqueles espaços.

Esta situação dá-se tanto quando uma parte da cidade se torna muito elitizada e é evitada pelas classes menos favorecidas, quanto em situações inversas, em que classes médias e altas evitam lugares chamados populares, ou em situaçóes em que grupos sociais considerados marginais (mendigos, usuários de drogas, desabrigados) ocupam espaços que são evitados, na medida do possível, por todas as classes sociais, numa situação paradoxal na qual, aqueles que, conforme Zukin (1980) estão destituídos de poder (econômico, político e de decisão) tem o poder de excluir os que tem aquele poder.

Os processos de reestruturação e remodelação urbana conhecidos sob o nome de qualificação, requalificação ou revitalização, ou pelo anglicismo gentrificação, permitem que os espaços urbanos retomem seu caráter público (Leite, 2002, p. 116), no entanto, têm sido alvo de muita discussão sobre tudo em função da eliminação destes espaços de moradores pertencentes às classes menos favorecidas.

O primeiro projeto de revitalização urbana citado pela literatura acadêmica é o do Barão Haussmann no século xix para adequar Paris às necessidades de circulação da sociedade industrial. Era um projeto destinado a "higienizar" a cidade (Choay, 2001), mas também a dificultar as barricadas operárias e facilitar a ação da cavalaria (Leite, 2002)

O conceito de gentrificação gentrifying no original em idioma inglês, é atribuído à socióloga (naturalizada) inglesa Ruth Glass, que o criou em 1964 quando descrevia o processo pelos quais os bairros operários de Londres começavam a ser "invadidos" pelas classes médias altas e baixas. Estas reformavam os sobrados, elevavam os preços do mercado imobiliário e, com isto, expulsavam a classe operária, levando a uma reconfiguração sócio cultural do bairro. $\mathrm{O}$ processo carrega uma conotação negativa, enfatizando a exclusão das classes 
menos favorecidas e são muitos os casos citados pela literatura e há inclusive movimentos internacionais contra a gentrificação. ${ }^{2}$

No entanto, é preciso retroceder um pouco para entender o processo anterior aos projetos de requalificação, que é a deterioração dos centros urbanos, devida ao processo de desindustrialização e de desmobilização das massas.

$\mathrm{Na}$ década de 1960 começa o chamado processo de desindustrialização e muitos protestos sociais (Harvey, 1989). A sociedade entra na era pós-industrial, em que o setor de serviços (o terceiro setor da economia) começa a prevalecer sobre o segundo. Grandes fábricas ficam vazias, depósitos ficam ociosos. Como parte de uma estratégia política de desmobilização das massas, são criados distritos industriais, centros administrativos, centros empresariais e outros, longe dos centros das cidades, de forma a impedir a concentração de operários, empregados, minorias que defendiam direitos, etc.

Como resultado, os centros das cidades são abandonados, aumentam os moradores de rua, o tráfico de drogas, a prostituição. Os centros das cidades passam a ser lugares perigosos, que devem ser evitados.

Algo similar aconteceu nas zonas portuárias, onde, devido à difusão dos containers, os prédios antes utilizados como depósitos de mercadorias ficam abandonados.

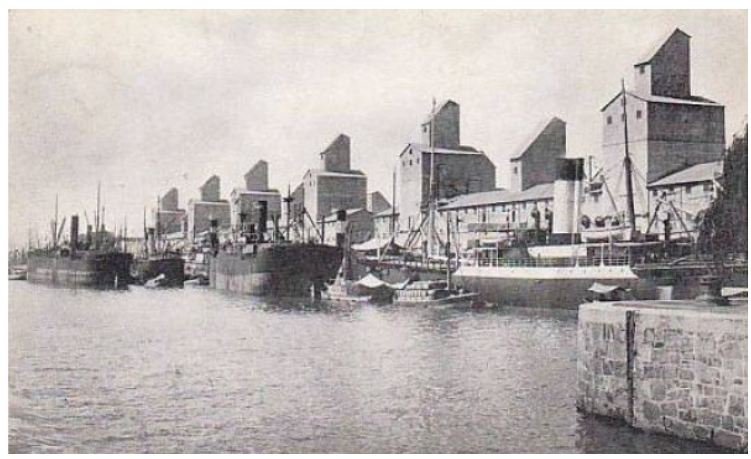

Figura 1. Puerto Madero, Buenos Aires, no ano de 1910 Fonte: Cartão Postal de domínio público ${ }^{3}$

2. Uma busca simples no google com o termo "against gentrification" no dia 21 de junho de 2013 deu 51.000 resultados.

3. Disponível em:

<http://commons.wikimedia.org/wiki/File:Puerto_Madero_Elevadores_de_Granos_\%28Olds\%29. jpg?uselang=es $>$ 


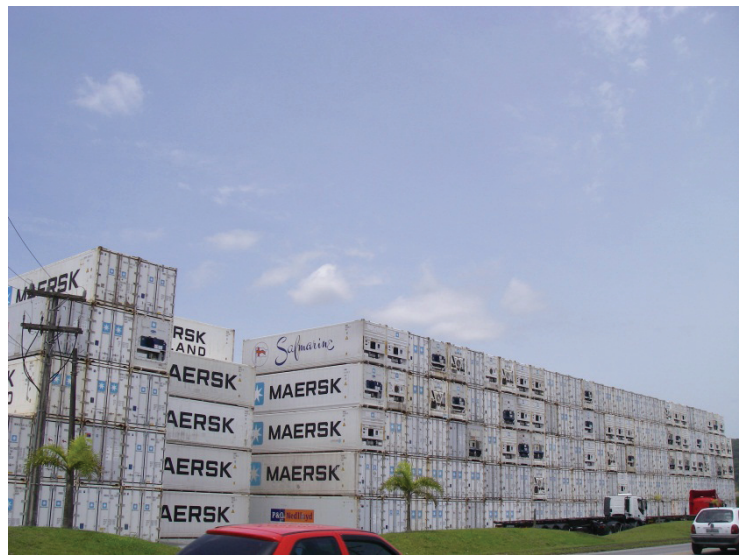

Fig. 2. Containers que dispensam depósitos de mercadoria Foto: A autora

A revitalização tem sido objeto tanto de críticas quanto de aprovação. A crítica segue às observações de Glass antes comentadas. Os lugares, antes da gentrificação, tinham moradores ligados à histórica local. Estas pessoas por sua vez tinham empregos ou subempregos nas redondezas e foram obrigados a mudar para bairros afastados o que os prejudicou não necessariamente pela perda do emprego em si mas pela dificuldade em aceder ao emprego, uma vez que dependem de transporte público, que é escasso ou inexistente. Este problema foi recorrente mesmo em lugares onde houve uma preocupação por realocar as pessoas em bairros populares construídos especialmente ${ }^{4}$.

De outro lado, se situam aqueles que defendem o processo, argumentando que, os primeiros trabalhos de revitalização urbana em Bolonha (Itália) foram projetos destinados à classe trabalhadora. (Gagliardi, 2011) Também deve-se tomar em conta que a exclusão social não surge exclusivamente a partir da gentrificação. $\mathrm{O}$ estágio do sistema capitalista nas últimas décadas do século $\mathrm{xx}$ levou à polarização socioeconômica. $\mathrm{O}$ capital e os fluxos das mercadorias manipulam os mercados de trabalho, criando o que Dear e Flusty (1999, p. 81) denominam com os neologismos de "cyburguesias" de um lado e os permanentemente marginalizados do outro, enquanto as cidades se transformam em espaços descontínuos e fragmentados, dominados por máfias transnacionais (ibidem).

4. E não é exclusivo de casos em que a população é realocada por questões de revitalização. Acontece também em casos em que são construidas moradias para danificados por desastres naturais. 
Em muitos lugares, a gentrificação permitiu a recuperação dos espaços públicos para uso da classe média, parques praças, a própria rua. Foram instalados também negócios, que dinamizaram a economia, além de proporcionar prazer estético, dimensão esta (a estética) que já era apontada por Simmel no início do século como altamente relevante para o indivíduo em sociedade (Simmel, 1991; Frisby, 1991) e que é reconhecida também como importante na pós modernidade, por autores como Harvey, por exemplo, que, após muito analisar a sociedade afirma que as práticas estéticas realmente importam (Harvey, 1990, p. 355), associando esta questão ao conceito de riqueza simbólica trabalhado por Krier a partir do conceito de capital simbólico de Bourdieu (apud Harvey, 1989, pp. 81-82). De acordo com Harvey, estas teorias explicariam o atual fascínio com o embelezamento, ornamentação e decoração urbanas pois estas são marcas de distinção social. Morar numa rua bonita, passear numa rua bonita, trabalhar numa rua bonita passa a ser parte do capital cultural, e - sendo que o padrão de beleza é o imposto pelo gosto das classes dominantes- passear numa rua bonita passa a ser também uma forma de aproxima-se daquelas. Isto pode ser explicado á luz do conceito de mimetismo social, atitude muitas vezes não deliberada que consiste na busca por autoestima e por reconhecimento dentro os estratos de mais poder aquisitivo (Sempere, 2008), podendo inclusive chegar a haver assimilação cultural.

Em muitos lugares, com a revitalização urbana evitou-se a destruição de prédios históricos e, por exemplo na Inglaterra, houve uma valorização de disciplinas como a história, a etno-história, a antropologia e geografia entre outras, que concorreram para a recuperação dos lugares históricos (Lumley, 1988, Urry, 1995) $)^{5}$. Mesmo autores que em um aspecto criticam a requalificação, admitem que "parece indiscutível que essa forma de intervenção urbana tem contribuído para criar uma certa rotina estética e uma vida pública” (Leite, 2002, p. 120).

A revitalização de espaços, com recuperação da memória tem levado também a revitalização de outros tipos de atividades, como festas ou rituais. Boissevain (1996) detectou isto nas suas pesquisas nas ilhas gregas, chamando estas atividades de rituais de revitalização. Pratts (1997) também encontrou

5. Não há estudos publicados no Brasil para reportar esta situação, no entanto sabe-se por evidência empírica que o Projeto Monumenta, pelo qual o centro de Porto Alegre foi requalificado teve muita participação da comunidade universitária. 
este comportamento na Espanha, dando ao fenômeno o nome de ativações patrimoniais. Mesmo que o lugar tenha sido revitalizado com intenção exclusivamente comercial, várias pesquisas mostram que seguiu-se um processo de valorização da memória coletiva, esta memória social, exterior ao indivíduo, estendida no tempo, que guarda arquivados fatos acontecidos há muito (Halbwachs, 1968).

Também tem levado a uma associação com o turismo, desde que os espaços revitalizados/gentrificados/requalificados ao mesmo tempo que se transformam em espaços de lazer urbano, se transformam em atrativos turísticos.

Os exemplos de lugares revitalizados ou gentrificados são inúmeros e crescem dia após dias. No Brasil na década de 1990 foram revitalizados o "bairro do Recife" centro histórico da cidade do mesmo nome (PE), o bairro pelourinho de Salvador (BA), o centro de São Luiz (MA), o centro de São Paulo. A revitalização deste último esteve a cargo de uma ONG, chamada Viva o Centro, que edita inclusive uma revista. Este movimento está caracterizado pela ativa participação da sociedade civil, o empresariado local e os bancos.

No mundo são tantos os projetos que já há críticas à reiteração de modelos ${ }^{6}$ e seria entediante reproduzir uma lista neste contexto. Basta dizer que a gentrificação das áreas portuárias tem, na atualidade, sua máxima expressão nos Estados Unidos onde há um projeto nacional de requalificação das mesmas.

Em muitos lugres houve efetiva participação da população. Um dos exemplos é o projeto da Baia de Boston, recuperada a partir de 1973 por uma associação mista fundada pela Liga de Mulheres Votantes e a Associação de Navios (Barretto, 2007).

No Brasil há casos bem sucedidos e também casos muito criticados, como é o do Pelourinho, na cidade brasileira de Salvador (BA). De acordo com Storatti (2005, pp. 205-223) tratou-se de um projeto oficial centralizador no qual as decisões foram tomadas sem a participação da população. Não houve revitalização porque transformou-se numa área somente turística e comercial na qual, na data da pesquisa acima referida, de 1.307 imóveis apenas 185 eram residenciais.

6. Harvey (1989, pp. 77-78) critica o projeto de Baltimore, dizendo que a cidade gentrificada tem "a mesma monotonia serial que o modernismo que supostamente reemplazaria". As paredes ficaram uniformiazadas com tijolo à vista e os mesmos faróis. 
No caso do centro de São Paulo, o projeto não atingiu seus objetivos de revitalização total porque não foram tomadas outras medidas estruturais para o manejo da cidade, e tampouco foi tomado em conta o problema social da mesma (Yazigi, 2006, p. 201).

No caso de Recife, pode-se dizer que o projeto foi bem sucedido, embora observa-se um certo deterioro no aspecto físico. Houve participação dos empresários locais e do poder público, assim como da cadeia de radio e televisão mais poderosa do pais, e o bairro passou a ser procurado como rua de lazer, inclusive a noite, coisa antes impensada. Passou a ter um calendário anual de atividades culturais, adquiriu visibilidade, e em 1998 foi tombada pelo Instituto do Patrimônio Histórico e Artístico Nacional - IPHAN (Leite, 2002) ${ }^{7}$. Na atualidade a rua congrega muitos bares e casas noturnas, há feira de artesanato aos domingos e, muito importante, não perdeu o movimento tradicional, continua havendo oficinas, escritórios, consultórios, atividades culturais e religiosas (nesta rua se encontra a sinagoga mais antiga da América Latina) ${ }^{8}$.

\section{Descrição do local e da metodologia empregada}

A Rua Vidal Ramos está localizada no centro histórico da cidade de Florianópolis, começando na lateral da Igreja Matriz, na R. Arciprestes Paiva estendendo-se por quatro quarteirões, até a R. Álvaro de Carvalho.

Pode-se dizer que a R. Vidal Ramos atualmente reúne as características que Relph (apud Dear \& Flusty,1999, p.66 ) atribui à paisagem urbana ${ }^{9}$ pós moderna: elegância, fachadas com aparência antiga, estilo, moda, reconexão com a história e a geografia locais, preferência para os pedestres.

A pesquisa de campo aconteceu durante uma semana, na qual duas pesquisadora observaram a dinâmica da rua, nos três períodos, de manhã, de tarde e de noite, em dias alternados. Foi realizado um registro fotográfico e foram realizadas entrevistas com diferentes informantes.

\footnotetext{
7. Foi também palco de disputas de legitimação de identidades e de espetacularização e comercialização da cultura (Leite, 2002).

8. A rua chamou-se Rua dos Judeus durante o período de administração holandesa da cidade (século XVII). Depois chamou-se Rua da Cruz e a partir de 1879 Rua do Bom Jesus (Kaufman, 2000)

9. O autor diferencia, em inglês cityscape que seria paisagem da cidade grande e townscape que seria a paisagem de uma cidade pequena e se refere a esta paisagem urbana pós moderma como townscape ou seja uma paisagem que tenta dar a sensação de um ambiente menos impessoal, mais aconchegante.
} 


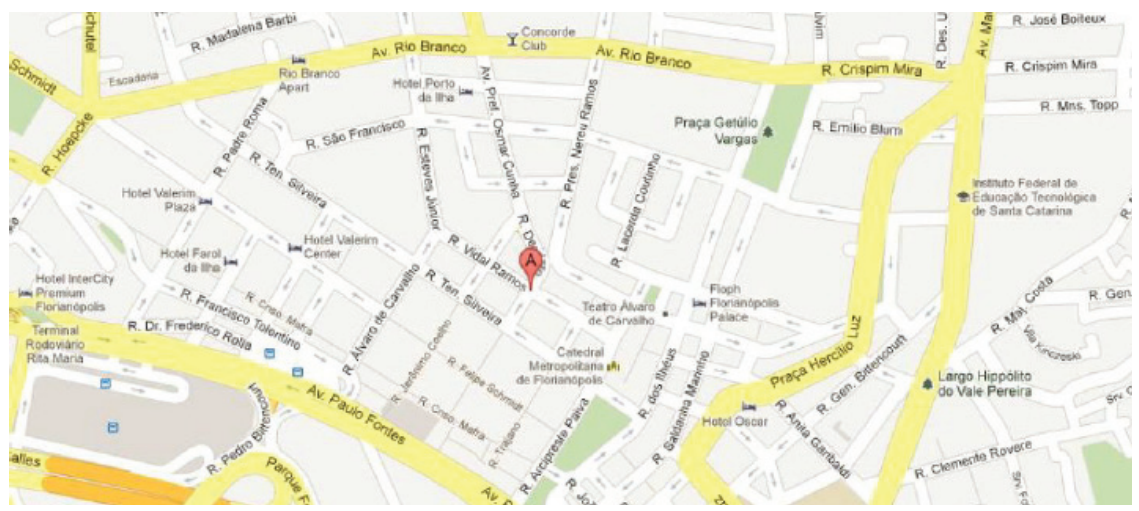

Figura 3. Mapa de localização da rua

Fonte: <www.maps.google.com>

$\mathrm{Na}$ categoria informantes foram entrevistados o idealizador do projeto, a atual líder do grupo de lojistas, uma das executoras do projeto, dois zeladores de prédios ${ }^{10}$ e duas pessoas idosas que moram num prédio localizado no final da rua, quando esta passa a ter o nome Esteves Júnior. Foram também entrevistados gerentes e atendentes de lojas assim como pedestres. Entre os primeiros, tentou-se equilibrar o ramo de lojas, entrevistando-se funcionários, gerente e/ ou proprietários de lojas de roupa, sapatos, bijuteria, farmácia, lanchonete, doceira, fábrica de carimbos. Também tentou-se equilibrar comércios mais novos com comércios mais tradicionais. Entre os pedestres tentou-se equilibrar idades e gênero. Preferiu-se abordar pessoas que estavam sentadas ou olhando vitrines, evitando-se parar pessoas que estavam andando ou distrair pessoas que estavam comprando. Para entrevistar os funcionários das lojas aguardou-se um momento em que não houvesse clientes dentro. Entre lojistas e pedestres foram entrevistadas 39 pessoas, somando um total de 46 entrevistados. Não se trabalhou com critério de amostragem mas com o critério da saturação de Bertaux (1980), pelo qual quando as repostas se repetem não acrescentando mais dados á pesquisa, considera-se número suficiente.

Tratou-se de um estudo de caso descritivo e exploratório, no qual não houve hipóteses; procedeu-se mediante observação não participante, assistemática anotada em diário de campo, utilizando-se como instrumentos o registro foto-

10. Os zeladores ofereceram informações interessantes, não apenas pelo contato que têm com os moradores mas porque os dois prédios estavam equipados com câmeras que permitiam uma visão total do quarteirão, portanto eles puderam nos informar sobre o movimento em geral. 
gráfico, e entrevistas semi estruturadas, que foram gravadas em meio eletrôni$\mathrm{co}^{11}$, e utilizou-se suporte documental e hemerográfico.

O roteiro de entrevistas procurou desvendar as representações de lojistas e transeuntes a respeito do processo de revitalização. Com cada entrevistado conversou-se sobre como lembrava a rua antes e como a enxerga agora, sobre se houve algum processo de exclusão, sobre a mudança ou não no público consumidor, sobre as diferenças percebidas no clima social em geral.

\section{Histórico do processo}

O projeto de revitalização da rua começou no ano de 2007 por iniciativa de alguns comerciantes juntamente com o então presidente da Associação Comercial e Industrial de Florianópolis- ACIF. Esta rua é paralela à três ruas comerciais, a Conselheiro Mafra e a Felipe Schmidt que concentram a maior parte do comércio do centro da cidade, e a Tenente Silveira que tem algumas lojas, muitas instituições financeiras, vários edifícios públicos, entre eles a Biblioteca Pública Municipal. Tratava-se de uma rua pouco frequentada, muitas pessoas entrevistadas comentaram que nunca tinham chegado até a mesma, embora fossem frequentadores do centro.

Como nos casos internacionais estudados nos processos de gentrificação, o centro comercial de Florianópolis foi afetado pela descentralização, pelo crescimento de centros comerciais em bairros (Canasvieiras, Ingleses, Lagoa da Conceição) além da instalação de três grandes shopping centers. Também diminuiu a quantidade de público circulante devido á descentralização da administração pública e empresarial, com a mudança dos escritórios para edifícios localizados em bairros afastados, como Cacupé.

O idealizador do projeto se inspirou numa rua de São Paulo, e inicialmente tentou realizar o projeto em outras ruas do centro que estavam precisando de revitalização. No entanto, não encontrou eco nos lojistas. Na Vidal Ramos foi diferente, desde que já havia há mais de dez anos, uma ideia de revitalizar a rua, e já os próprios interessados haviam realizado pesquisas em outras cidades de Santa Catarina. Trata-se de lojas pequenas, de micro empresários, em sua maioria inquilinos dos locais, havendo apenas uma loja que é franquia de uma

11. Somente uma entrevista não foi gravada, concedida por uma senhora de 84 anos que não achou que seu depoimento pudesse ser interessante. No entanto concedeu duas horas do seu tempo à pesquisadora, tomando café e passeando pela rua de braço dado. 
grande empresa. O projeto, inaugurado em março de 2012, chamou-se shopping a céu aberto, e a forma de gestão é a mesma de um shopping, com promoções em comum e divulgação nos meios em conjunto, de forma a otimizar os custos de administração e a obtenção de benefícios para todos ${ }^{12}$. $\mathrm{Na}$ atualidade, de acordo com documentos exibidos e depoimento da presidente da associação $70 \%$ a $80 \%$ dos comércios aderiram à padronização e 35 lojas participam do programa de capacitação do Sebrae ${ }^{13}$.

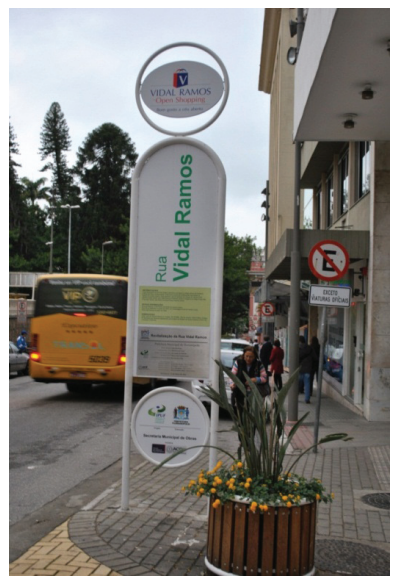

Figura 4. Começo da Rua, na esquina com a rua Arciprestes Paiva Foto: Pesquisadora

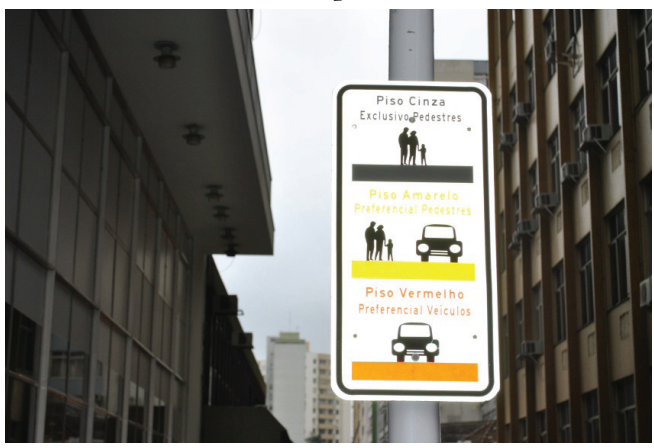

Figura 5. Indicação de sinalização de rua Foto: Pesquisadora

12. Por exemplo um convênio para que o recolhimento de lixo aconteça em determinado horário e que todos os lojistas coloquem o lixo em determinado lugar nesta hora.

13. Há 56 lojas na rua e somadas as lojas em subsolos são 74 
Foi feita uma parceria público-privada. Foi realizado um convênio pelo qual a Prefeitura Municipal realizou a infraestrutura, colocou esgotamento sanitário, os cabos de luz subterrâneos e fez o pavimento, investindo em torno de $\mathrm{R} \$$ 500.000,oo. O Instituto de Planejamento Urbano de Florianópolis- IPUF fez o desenho urbano, planejou os toldos e placas, a sinalização da rua. A ACIF destinou uma funcionária para auxiliar, dar entrada no processo, articular os comerciantes, "lidar com o imediatismo", comenta, porque foram dois anos de obras, com diminuição do movimento e os vizinhos reclamavam das escavações. Cada um dos imóveis revitalizados recebeu uma cor diferente. Cada lojista pagou as despesas com a própria fachada, com o toldo e a placa, e a ACIF pelos bancos, as jardineiras e as lixeiras investindo em torno de $\mathrm{R} \$ 350.000$,oo. A partir de uma parceria com o jornal Notícias do Dia, duas grandes empresas (Koerich e Zita) doaram as plantas ${ }^{14}$ e os lojistas atualmente se ocupam de molhá-las. Foi realizado um convênio com o Serviço Brasileiro de Apoio às Micro e Pequenas Empresas -Sebrae para realizar um programa de treinamento e capacitação com os lojistas e seus empregados, para atendimento em geral e foram ministrados cursos de vitrinismo. Também o Sebrae realiza ações, como desfiles ou promoções e o jornal Notícias do Dia publicou diversas matérias entre os anos 2011 e 2012, com entrevistas a participantes do projeto e transeuntes.

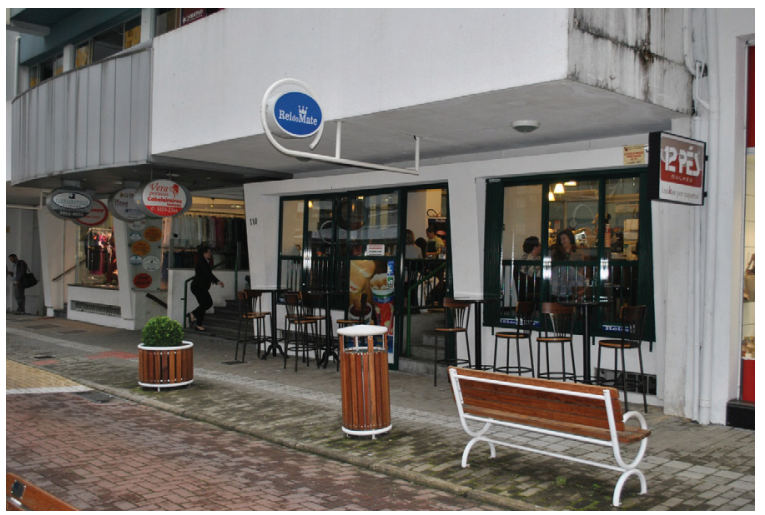

Figura 6. Detalhe de Banco, Lixeira e Floreira, placa padronizada e calçada acessível. Foto: Pesquisadora

14. Parceria entre Notícias do Dia e Vidal Ramos traz flores para Florianópolis. Disponível em: <http://www.clickric.com.br/ric.com/noticias.asp?id_cat=10\&id=6089\&estado=sc $>$ 
$\mathrm{Na}$ atualidade está sendo formada uma associação dos lojistas da rua para manter a limpeza dos toldos e a integridade do mobiliário e já o projeto está sendo copiado por outras ruas perpendiculares. Foi feito um trabalho junto aos lojistas para que não coloquem lixo nas lixeiras e estão propondo uma lei para que não possa ser colocado lixo durante o dia, estão sendo colocados bicicletários, doados pela empresa que fez os toldos.

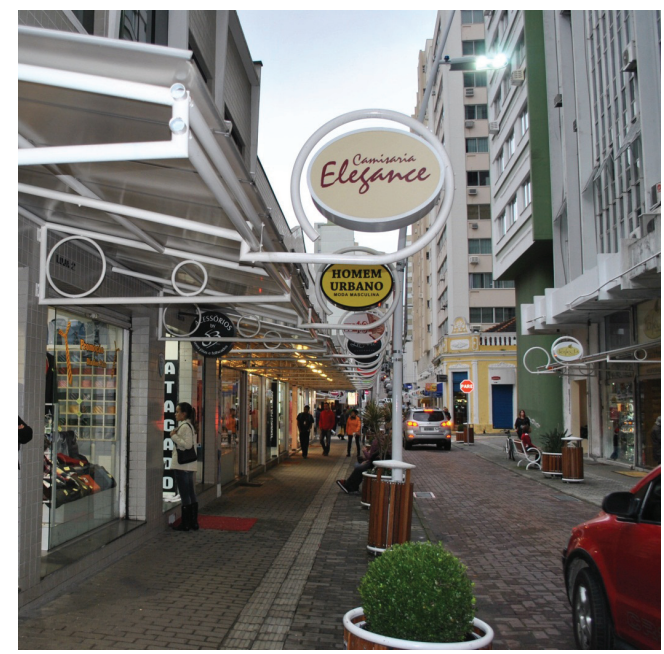

Figura 7. Toldos e placas padronizados Fogo: Pesquisadora

A rua passou a ser um espaço de trajetos, ou seja fluxos recorrentes (Magnani, 2002).Pessoas que transitavam pelas ruas paralelas passaram a utilizar a Vidal - como é chamada por todos- porque "gostam mais". Utilizando ainda os conceitos de Magnani, pode-se dizer que está se constituindo numa mancha de lazer urbano, com bancos para sentar e cafés.

Os toldos, além de darem uniformidade estética, protegem da chuva e do sol, o que, conforme os lojistas, propicia o aumento das vendas nos dias de mau tempo ${ }^{15}$. Os moradores e transeuntes elogiaram também a proteção dos mesmos. Outra função dos toldos é a semiótica.

15. Embora a pesquisa estivesse finalizada, constatou-se empíricamente no verão que os toldos eram muito elogiados nos dias de extremo calor e sol. 
Sinalizam quem faz parte do projeto e quem não, o que tem levado a que pessoas que não quiseram em princípio aderir ao projeto, agora queiram participar.

Os transeuntes entrevistados lembram que era uma rua comum, e a maioria ou bem não transitava por ela, ou sequer a conhecia. Os moradores não transitavam por ela a não ser o imprescindível, a qualificam como "abandonada", havia andarilhos, pouca iluminação à noite.

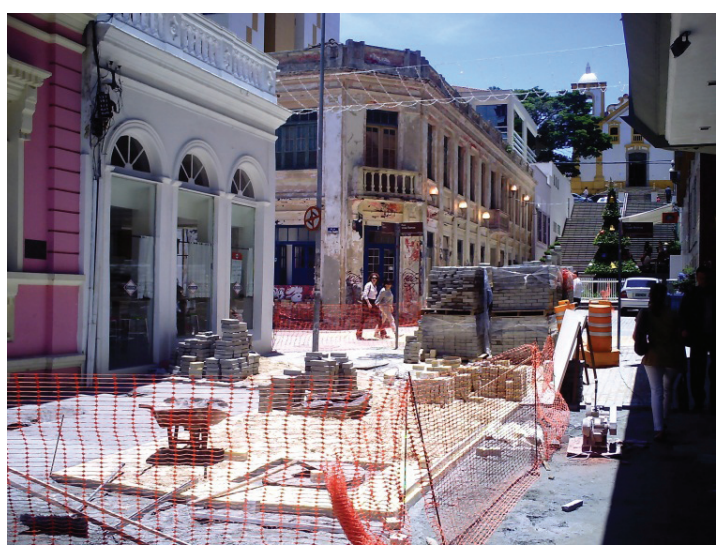

Figura 8. Prédio abandonado em 2010

Foto: Luiz Fontoura. Cedida por Rose Coelho

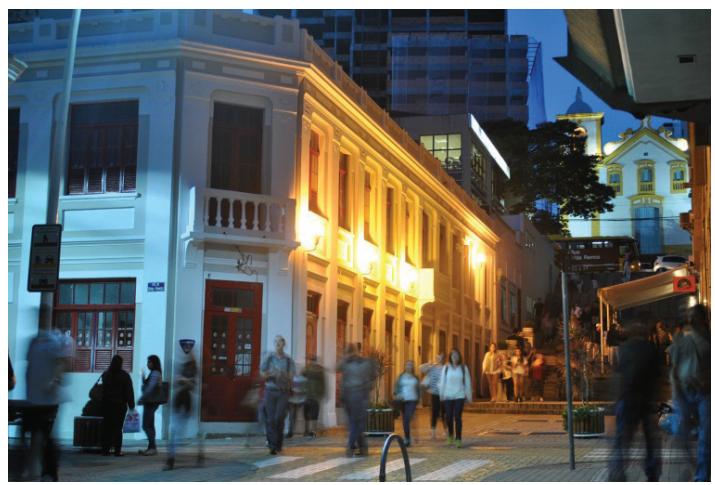

Figura 9. O mesmo prédio restaurado

Foto: Pesquisadora 
Já os lojistas lembram que era uma rua desorganizada, suja, pacata, "esburacada", perigosa a partir do entardecer, "dava medo na hora de fechar a loja" declara uma atendente de relojoaria; os dias de chuva, alagava, contam alguns, "os esgotos retornavam" declara outro entrevistado. Uma funcionária de uma farmácia chega a dizer que era "horrível", que dias de chuva alagava. Comentam que havia roubos, quebra de vitrines para levar pequenos objetos, "pesca" de objetos pelas vitrines "uma loja cuidava a outra para não haver assaltos" comenta uma funcionária, enquanto outras relatam que tinham medo na hora de abrir as lojas de manhã, porque havia pessoas dormindo na rua, ou na hora de fechar a noite quando havia muito pouco movimento. Um comerciante comentou que sua loja foi assaltada duas vezes e outra que disse que havia lojas que tinham sido assaltadas quatro ou cinco vezes ${ }^{16}$.

De acordo com todos os entrevistados a rua melhorou muito de todo ponto de vista.

Respostas como "adorei", "amei", "ficou maravilhosa" apareceram reiteradamente nas entrevistas com os pedestres e moradores, assim como os adjetivos agradável e gostosa.

"Essa beleza e essa atenção que está sendo dada para a rua da sensação de segurança, da vontade de comprar, dá vontade de tomar um café" diz a gerente de uma loja de roupas. $\mathrm{O}$ dono de uma lanchonete, por sua vez, qualifica a rua como "estilosa" acrescentando que "a rua ficando harmoniosa, fica mais harmonioso o ambiente de trabalho".

Observou-se muito movimento dentro das lojas, em algumas especialmente mais do que em outras até o ponto de não ser possível encontrar um momento oportuno para realizar entrevistas com os funcionários e/ou gerentes ${ }^{17}$.

Os lojistas entrevistados não reportam nenhum processo de exclusão de antigos lojistas ou de substituição de lojas antigas por novas empresas. Agregaram-se, sim, novas lojas mas sem o fechamento das tradicionais, acrescentando que se algumas fecharam foi porque eram caras ou porque estavam num ramo onde havia muita concorrência ${ }^{18}$. Tampouco houve denúncias sobre aumento excessivo do preço dos aluguéis, que, estimam que está na casa dos $10 \%$; pelo

16. Desde que está-se trabalhando com percepção, não importa o número exato.

17. Foi observado, mas não tentou-se aprofundar no assunto, que a parte mais movimentada da rua é a quadra entre a Deodoro e a Trajano, embora nas outras quadras há a mesma quantidade de lojas.

18. Somente uma entrevistada comentou que houve muito fechamento de lojas mas não soubre precisar. 
contrário, dizem, há mais pessoas procurando alugar. Afirmam que houve aumento no movimento da rua, embora não necessariamente do faturamento ${ }^{19}$ mas todos entendem que isso é uma questão de tempo; estão contentes, há melhor clima de trabalho, vêm à loja com mais vontade ${ }^{20}$. Estão orgulhosos de que a rua está sendo "comentada", inclusive por estrangeiros, estão contentes com os cursos que estão fazendo, com o clima de colaboração que se instalou. Também estão contentes porque o público "que tinha-se afastado do centro" (passando a ser consumidor de shopping centers) está voltando. Isto sem prejuízo da clientela anterior, que continua a frequentar os locais.

Também está acontecendo um fato que os lojistas não esperavamะ a entrega de curriculum por parte de funcionários que estão trabalhando em "lojas boas" dos shoppings e que manifestam que gostariam de trabalhar em lojas boas do centro.

Os lojistas também comentaram os elogios ouvidos dos clientes, como agora estes preferem "andar na Vidal"; avaliam que como as pessoas "veem bonito, se sentem mais seguras".

Perguntou-se aos lojistas o que achavam das pessoas que simplesmente vinham para sentar nos bancos e eles disseram que não se incomodam porque mesmo essas pessoas acabam comprando alguma coisa.

Quase todos os pedestres entrevistados dizem não encontrar diferença de preços entre as lojas da Vidal Ramos e as outras lojas do centro, observando que há também lojas caras e lojas baratas nas outras ruas. A observação empírica também permitiu constatar que os preços não são diferentes e até havia lojas com descontos oferecendo preços mais baratos do que em outras lojas da cidade. Inclusive a zeladora de um prédio, entrevistada na qualidade de informante, disse que ela comprava em algumas lojas da Vidal.

As pessoas de um modo geral acham o comércio "chique", sofisticado. Também encontraram-se pessoas da terceira idade que observaram que o tipo de roupa era mais adequado do que o oferecido no comércio "da Felipe"21. Uma senhora comentou que morava no continente mas somente comprava numa

19. Um lojista comentou que suas vendas tinham aumentado e que suas vendedoras que trabalham a comissão estavam ganhando o dobro que no ano anterior e houve outros (poucos) que também comentaram que o faturamento tinha aumentado.

20. Em meio ao entusiasmo generalizado somente duas atendentes de uma pequena loja disseram que para elas nada tinha mudado.

21. A rua paralela já mencionada no início do artigo, que concentra maior quantidade de lojas. 
loja específica da Vidal por esta razão. A observação empirica confirmou que há roupa mais sóbria, e para manequins maiores, mais de acordo com um público feminino de idade madura.

Os bancos são alvo de elogios. As pessoas utilizam expressões como "é demais poder sentar". E um senhor que usava muletas comentou que sua vida seria mais fácil "se toda rua fosse assim". Uma entrevistada observou que nesta rua pode-se usar salto alto ${ }^{22}$. Comparam a rua com um shopping com a vantagem de que não está fechado."Moro em apartamento, para mim passear no shopping não tem graça" diz uma entrevistada que aguardava que o esposo passasse para pega-la com o carro.

Dentre os transeuntes entrevistados somente uma pessoa, que identificou-se como socióloga moradora de uma cidade vizinha criticou o projeto urbanístico avaliando que os bancos tinham ficado muito próximos da rua o que era perigoso porque alguém podia ser atropelado por um carro. Ela estava sentada na mesa de um café tradicional da rua não para consumir mas para descansar, não o fazendo no banco por temor. Por uma grande coincidência no momento da entrevista um carro saiu de uma garagem e precisou manobrar para poder contornar um banco e entrar efetivamente na rua. Os demais entrevistados avaliaram positivamente o lugar, dizendo que o frequentavam para passeio ou descanso.

Uma funcionária de um escritório entrevistada enquanto estava descansando num banco aguardando o horário de retornar ao trabalho comentou que fazia questão de almoçar todos os dias num lugar diferente, fazendo do seu horário de almoço na Vidal um momento de lazer. Um senhor idoso, aposentado que descansava enquanto aguardava a hora de uma consulta médica numa clínica próxima disse estar emocionado de ver as mudanças.

Observou-se que muitas pessoas se cumprimentavam e que havia grupinhos pequenos nas portas principalmente de lanchonetes e cafés e um jovem que estava com quatro amigos comentou que o projeto coincide com a maneira de ser dos florianopolitanos. "É da cultura do manezinho ${ }^{23}$ mesmo sentar, conversar..." ${ }^{24}$.

22. Informação importantíssima desde que, de fato, nas ruas paralelas a estrutura das calçadas dificulta o uso do salto, que ora encaixa em juntas, ora desequilibra nos paralelepípedos.

23. Nativo de Florianópolis (SC).

24. De fato há em Florianópolis uma tradição de reunir-se nas praças, ou em determinadas esquinas. Exemplos de pontos de reunião são o "senadinho" na esquina das Ruas Felipe Schmidt com Trajano, e Rua dos Ilhéus com Tenente Silveira, onde há inclusive mesas para jogar dominó e damas, que reúnem muita gente. 
O zelador de um prédio comentou que ao entardecer vários vizinhos, mais idosos, desciam e ficavam na rua, na frente do prédio, confraternizando.

Um dado importante é que os prédios foram beneficiados com a instalação de esgotamento sanitário, e uma nova rede pluvial, desde que nos últimos anos quando chovia a rua alagava. Também a iluminação pública foi trocada colocando-se lâmpadas led que tem mais luminosidade e, portanto, oferecem mais segurança a noite.

Uma das respostas que mais surpreendeu aos pesquisadores foi quanto ao estreitamento da rua para a passagem de carros e à proibição de estacionamento ao longo de praticamente toda a rua. Desde que no Brasil a cultura do automóvel está muito enraizada desde a segunda metade do século xx (Maricato; Rocha, 2008) esperava-se ouvir muitas queixas a respeito, o que não aconteceu. Os lojistas e os pedestres entrevistados utilizaram adjetivos como ideal, ótimo para não haver acidentes e para que os pedestres possam estar a vontade.

Mais ainda, muitos disseram que a proibição de carros deveria ser total, embora entendam que isso não é possível porque há prédios com moradores. Já os zeladores dos prédios comentaram que os moradores se queixavam muito, que era muito transtorno para idosos ou portadores de necessidades especiais ${ }^{25}$. No entanto um dos entrevistados, morador idoso, disse que para ele estava perfeito, que ele só utilizava o carro aos domingos para ir visitar os filhos e que tendo "tudo perto" não precisava de carro. Uma entrevistada que trabalha em escritório comentou que os colegas se queixavam bastante ${ }^{26}$ por não ter onde estacionar, fundamentalmente em dias de chuva, e que alguns inclusive estavam optando por vir de ônibus ao trabalho, mas agregou que "cada um deve solucionar seus problemas, a rua está ótima do jeito que está”.

Foram encontrados também contra usos: "usos que podem alterar a paisagem e imprimir outros sentidos [...] aos lugares e espaços da cidade" (Leite, 2002, p. 121). Foram observadas (e entrevistadas) várias pessoas que estavam sentadas nos bancos públicos e até uma que estava sentada numa mesa de café, sem consumir, portando sacolas de lojas populares que não estão exatamente na Vidal, mas em ruas que cortam a mesma. Estas pessoas não são consumi-

25. O zelador de um prédio comentou que existe uma vaga rotativa para ser utilizada para asenso e descenso de passageiros, mas que as pessoas a ocupam como estacionamento e "o pessoal da zona azul (fiscalização) não aparece".

26. E disse isso numa entoação bem enfâtica. 
doras das lojas da rua, porém a utilizam como trajeto e também como espaço de descanso e lazer.

Foram observadas também contravenções, como carros ou motos estacionados na calçada e também foi constatado o informado pelos entrevistados sobre a dificuldade para uniformizar a conduta respeito ao lixo.

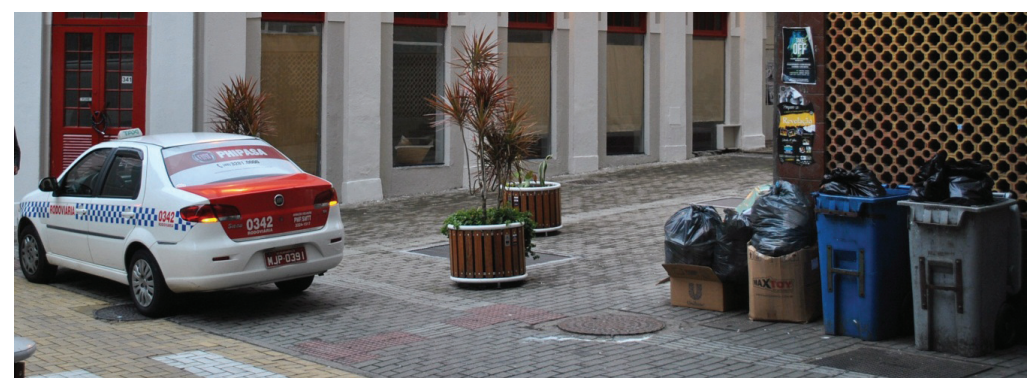

Figura 10. Taxi sem motorista, estacionado na calçada, e lixo Foto: Pesquisadora

Durante o trabalho de campo não foram encontrados moradores de rua na própria Vidal Ramos. Os pesquisadores foram, sim, abordados por vendedores ambulantes e pedintes na esquina com a Rua Deodoro, o que coincide com o fato de haver, poucos metros depois, na esquina desta com a Tenente Silveira, um prédio público com um grande vão, utilizado como abrigo e citado por todos os entrevistados como sendo o principal problema ainda não solucionado no bairro sobre tudo porque há consumidores de $\mathrm{crack}^{27}$

Tampouco durante o trabalho de campo foram encontrados agentes policiais e este foi um ponto sobre o qual houve divergências entre os entrevistados. Para alguns a segurança melhorou, "agora há polícia", "as câmeras dão conta da vigilância". A atendente de uma loja comentou que dias atrás tinha deixado o tapete esquecido na rua, e no dia seguinte o tapete estava ali mesmo, quando antes não podia nem deixar coisas na vitrine porque eram roubadas. Os escri-

27. Cabe aqui mencionar uma questão que surge a partir da leitura dos trabalhos de Zukin (1991;2000) em que a autora se refere aos que tem poder e os que não têm, sendo que os primeiros seriam os privilegiados que provocam os processos de gentrificação. Não será objeto desta pesquisa, mas o tema merece uma pesquisa específica, desde que os moradores de rua, neste caso, tem, sim poder, o poder de amedrontar e de mudar os hábitos dos outros; um poder coercitivo que pode não estar associado a fatos reais mas ao imaginário das pessoas, mas que existe. 
turários que trabalham nesta rua dizem se sentirem mais seguros quando acaba o expediente no fim da tarde.

Para outros, no entanto, "houve policiamento no início e agora não há mais", enquanto que outros declaram que "há somente policiamento aos sábados" ou "vem polícia só quando algo acontece". Uma atendente de uma loja de acessórios comentou que na semana anterior tinha havido "três mulheres elegantes dando golpe".

Também há informações encontradas quanto aos moradores de rua. Uma das articuladoras do projeto comentou que houve resistência ao projeto de colocar bancos porque as pessoas temiam que se transformasse em "dormitório de mendigos". Ela disse que foi pensado um desenho de banco que não seja confortável para dormir e que não havia mendigos dormindo. No entanto a zeladora de um prédio comentou que quando ela chega às $6 \mathrm{~h}$ da manhã, os mendigos levantam e vão embora. A zeladora frisa que eles deixam tudo em ordem, o que coincide com o depoimento da presidente da associação que disse ter ouvido dois mendigos elogiando as lixeiras.

Outro ponto sobre o qual houve divergências foi o movimento da rua aos sábados. De acordo com os depoimentos, os moradores utilizavam bastante a rua nesse dia; no entanto esta situação não foi verificada empiricamente durante uma permanência de três horas no local.

\section{Considerações finais}

Do ponto de vista da metodologia da pesquisa, é interessante destacar que as divergências quanto à questão da segurança confirmam que os depoimentos não são suficientes, que é necessário também haver observação e documentação, o que reafirma a convicção da pesquisadora de que deve-se trabalhar com técnicas variadas para ter uma representação o mais fiel possível dos fatos, uma vez que a subjetividade interfere grandemente na pesquisa sócio antropológica.

Constatou-se uma vez mais que em qualquer grupo social, por pequeno que seja, há tensões entre diferentes atores que tem diferentes interesses (ou desinteresses) cuja percepção do mundo real está contaminada pela subjetividade.

No que diz respeito ao projeto, é significativo que o idealizador do mesmo seja bacharel em história, o que reforça a ideia já formulada em trabalhos 
anteriores sobre o papel das pessoas, dos seus ideais e da sua subjetividade na realização de projetos, sejam culturais ou comerciais ${ }^{28}$.

Quanto a um balanço sobre como as pessoas percebem o processo de gentrificação, a visão positiva leva a reforçar uma premissa subjacente à pesquisa, que também foi objeto de trabalhos anteriores ${ }^{29}$.

A gentrificação é uma forma de recuperar lugares denegridos pelo próprio processo da sociedade capitalista e do neo liberalismo, que provocou o deslocamento do capital investido nas indústrias para o mercado financeiro e, parafraseando Zukin ${ }^{30}$, o aparecimento de ilhas de pobreza em mares de riqueza e vice-versa. A gentrificação não é um processo destinado a melhorar a vida das classes menos favorecidas, mas tampouco a vida destas pessoas melhora deixando os centros urbanos e portuários abandonados.

O termo gentrificação que indica enobrecimento, elitização, de repente não seja o mais adequado para definir todos os tipos de revitalização urbana. Colocar em igualdade de condiçóes um processo como o relatado por Glass, em que a população de origem operária era expulsa de suas casas pela especulação imobiliária e um processo em que barracões abandonados se transforam em universidades, cinemas, restaurantes e escritórios ${ }^{31}$ não parece ser totalmente adequado. Quem sabe é necessário começar a separar, dentro dos processos de requalificação urbana o que é elitização e o que é recuperação de áreas degradadas transformadas em cracolândias ou simplesmente abandonadas que se tornam refúgio de moradores de rua, que também precisam ser diferenciados entre aqueles marginalizados pela sociedade e aqueles que ali moram por opção.

A sociedade capitalista levou à existência de grupos marginais, seja pela pobreza ou pela anomia. A requalificação urbana não inclui estes despojados, mas inclui uma classe social que tem sido também prejudicada a partir do último quartel do século xx, a classe média, que teve seu melhor momento entre o final da segunda guerra mundial e a crise do petróleo de 1972. Enquanto não

28. A pesquisadora já viu casos semelhantes em pesquisa sobre museus em que os diretores faziam a diferença, e na constituição de um balneário turístico, onde o idealismo de um empreendedor foi determinante. No entanto é curioso neste caso particular que o projeto de um historiador não foi caompanhado de um trabalho de recuperação da história da rua e seus moradores, embora consultado a respeito comentou que está nos seus planos futuros.

29. Em Barretto (2007) a pesquisadora já emitiu sua opinião a respeito dos aspectos positivos da revitalização.

30. Zukin (1993) diz que a gentrificação colocou ilhas de renovação em mares de decadência.

31. Alusão a Puerto Madero, em Buenos Aires, Argentina 
houver projetos políticos para incluir todas as classes sociais, porque o modelo econômico escolhido é excludente, projetos para incluir as classes médias são benvindos.

\section{Referências}

Barretto, Margarita. Turismo y Cultura. Relaciones, contradicciones y expectativas. Colección Pasos Edita, n 1, El Sauzal, Tenerife, ACAy PASOS. 2007. E-book disponible en: <http://www.pasosonline,org/Publicados/ pasosoedita/PSEdita1.pdf $>$.

Bertaux, D. "L'Aprroche biographique: sa validité méthodologique, ses potentialités". Cahiers Internationaux de Sociologie XIX. Paris:PUF, 1980.

Boissevain, Jeremy. Coping with tourists. European reactions to mass tourism. Oxford:Berghahn Books, 1996.

Choay, Françoise. A alegoria do patrimônio. São Paulo: Unesp, 2001.

Dear, Michael; Flusty, Steven. "The postmodern urban condition". In: Featherstone, M. \& Lash, S. (orgs.) Spaces of Culture. City-NationWorld. London: Sage, 1999, pp. 64-85.

Frisby, David. "The aesthetics of modern life: Simmel's Interpretation”. Theory, Culture and Society, Vol 8, London: Sage, 1991, pp. 73-93.

Gagliardi, Clarissa M. R. "Um grande projeto entre o mar e as colinas: a renovação urbana da cidade italiana de Gênova”. Cadernos Metropole, São Paulo, v. 13, n. 25, pp. 123-143, jan/jun 2011.

Halbwachs, Maurice. La mémoire collective. Paris: Pres Univ de France, 1968 Harvey, David. The condition of Postmodernity. Cambridge: Cambridge University Press, 1989 (reimpressão 1990).

Kaufman, Tânia Neumann. Passos perdidos - História recuperada: a presença judaica em Pernambuco. Recife: Edição do Autor, 2000.

Leite, Rogério P. “Contra usos e espaço público: notas sobre a construção social dos lugares na Manguetown”. Revista Brasileira de Ciências Sociais, Vol 17, n. 49. Junho 2002.

Lumley, Robert. The museum time machine. London:Routledge, 1988.

Magnani, José G. C. "De perto e de dentro. Notas para uma etnografia urbana”. Revista Brasileira de Ciências Sociais. Vol 17, n. 49, junho 2002. 
Maricato, Ermínia; Rocha, Ronai P. da. "A cultura do automóvel”. Ciência e Ambiente, n. 37. UFMG, Julho-Dezembro 2008.

Prats, Llorenç. “Concepto y gestión del patrimonio local”. Cuadernos de Antropologia Social, n. 21, 2005, pp. 17-35.

Sempere, Joaquin. "La explosión de las necesidades en el marco del sistema socioeconómico". Papeles. Número Especial. 102, 2008, pp. 103-109.

Simmel, Georg. "The problem of style”. Theory, Culture an Society, Vol 8, London:Sage, 1991pp. 63-71.

Sotratti, Marcelo A. Pelas ladeiras do Pelô: A requalificação urbana como afirmação de um produto turístico. Dissertação de Mestrado em Geografia. IG. Unicamp, 2005.

URRY, John. The tourist gaze. Leisure and travel in contemporary societies. London:Sage, 1995.

YAzigi, Eduardo A. Esse estranho amor dos paulistanos. Requalificação Urbana, Cultura e Turismo. Brasília: CNPq/São Paulo:Global, 2006.

Zukin, Sharon. Landscapes of power. Berkeley: University of California Press.

\section{Entrevistas:}

Dilvo Tirloni. Ex presidente da ACIF e um dos idealizadores do projeto.

Rosângela J. M. Coelho (Rose Coelho). Presidente da Associação de Lojistas da R. Vidal Ramos e uma das idealizadoras do projeto.

Isabel C. Guenther. Ex funcionária da ACIF e uma das executoras do projeto.

S. Zenon (Engenheiro aposentado). Morador há 38 anos. Cresceu na R. Jerônimo Coelho, que cruza Vidal Ramos e agora está também em processo de revitalização.

Noemia B. Brasil (84 anos). Moradora há 30 anos.

Lojistas.

Transeuntes. 